\title{
Association of lower urinary tract symptoms and $O A B$ severity with quality of life and mental health in China, Taiwan and South Korea: results from a cross-sectional, population-based study
}

Kyu-Sung Lee ${ }^{1}$, Tag Keun Yoo ${ }^{2 *}$, Limin Liao ${ }^{3}$, Jianye Wang ${ }^{4}$, Yao-Chi Chuang ${ }^{5}$, Shih-Ping Liu ${ }^{6}$, Romeo Chu ${ }^{7,8}$ and Budiwan Sumarsono ${ }^{7}$

\begin{abstract}
Background: Lower urinary tract symptoms (LUTS) and overactive bladder (OAB) symptoms have a substantial effect on quality of life (QoL). We report QoL and mental health results from a LUTS prevalence study in three Asian countries.

Methods: A cross-sectional, population-representative, internet-based study among individuals aged $\geq 40$ years in China, Taiwan and South Korea. Instruments included: Overactive Bladder Symptom Score (OABSS); International Prostate Symptom Score (IPSS); other International Continence Society (ICS) symptom questions; health-related QoL 12-item short-form (HRQoL-SF12v2); Work Limitations Questionnaire (WLQ); Hospital Anxiety and Depression Scale (HADS). Presence of LUTS was determined according to ICS criteria, with three symptom groups (storage, voiding and post-micturition). Post-stratification weighting matched the age and sex population distribution per country. Initial data analyses were based on descriptive statistics. Significance testing undertaken post hoc included: independent-samples t-test (differences in HRQoL between sexes and between individuals with/without LUTS; relationship between HRQOL score and OABSS; differences in HADS anxiety and depression scores between individuals with/without LUTS; association between HADS anxiety/depression scores and OABSS), chi-square test (association between LUTS prevalence and workplace productivity) and analysis of variance (differences in HRQoL score and in HADS anxiety/depression scores between individuals with different symptom groups, association between HADS anxiety/depression scores and IPSS).

Results: In total, 8284 participants were included. HRQoL scores were significantly worse $(p<0.001)$ among individuals with versus without LUTS (ICS criteria): mean physical health domain scores were 61.1 (standard deviation [SD], 20.1) and 76.7 (17.0), respectively; corresponding mental health domain scores were 34.8 (12.7) and 43.7 (10.7). Workplace productivity was best among individuals without LUTS (difficulties reported by $2-3 \%$ of individuals), and worst in those with all three ICS symptom groups (difficulties reported by $29-38 \%$ of individuals; $p=0.001$ ). Mean HADS scores showed significantly worse $(p<0.001)$ levels of anxiety and depression among individuals with versus without LUTS: anxiety, 6.5 (SD, 3.7) and 4.0 (3.3); corresponding mean depression scores were 6.8 (4.3) and 4.2 (3.6). Increasing OAB severity was also associated with decreasing HRQoL physical and mental health scores.

(Continued on next page)
\end{abstract}

\footnotetext{
*Correspondence: ytk5202@eulji.ac.kr

${ }^{2}$ Department of Urology, Nowon Eulji Medical Center, Eulji University School

of Medicine, 68, Hangeulbiseok-ro, Nowon-gu, Seoul, Korea

Full list of author information is available at the end of the article
} 
(Continued from previous page)

Conclusion: LUTS and increasing OAB severity are both associated with impaired QoL, reduced workplace productivity, and increased tendency towards anxiety and depression. These results highlight the need to ensure that individuals with LUTS receive appropriate, effective treatment.

Trial registration: ClinicalTrials.gov identifier: NCT02618421, registered 26 November 2015 (retrospectively registered).

Keywords: Asia, Epidemiology, Lower urinary tract symptoms, Mental health, Prevalence, Quality of life

\section{Background}

Depending on definition, lower urinary tract symptoms (LUTS) are reported to affect over half of the world's adult population [1-4]. Although these symptoms are not lifethreatening, associations with conditions such as obesity and type 2 diabetes have been reported [5] and they are often bothersome. The potential effects of LUTS are wideranging, from impairment of sleep and personal relationships to reductions in emotional well-being and workplace productivity [6]. Consequently, LUTS is associated with impaired quality of life (QoL) [7-9].

Studies from around the world have shown that the impact of LUTS on QoL may be manifested in overall QoL scores, either generic or disease-specific, as well as specific dimensions such as vitality, social functioning, physical activities and mental health [7-16]. The impact of moderate LUTS on QoL has been likened to that of diabetes, hypertension or cancer [12]. LUTS have also been shown in a variety of countries to be associated with increased rates of mental health issues, specifically depression and anxiety $[5,7,9,17]$. The relationship between LUTS and depressive symptoms appears to be robust regardless of sex/ethnicity [18].

The substantial impact of LUTS on QoL reinforces the need for their treatment, and indicates the potential benefits of effective intervention. In addition, treatment of LUTS has been shown to improve QoL [19]. However, many patients with LUTS do not seek healthcare [20] and LUTS therapy may not be regarded as a high priority by primary care physicians [21].

We conducted a study to determine the prevalence of LUTS in the population aged $\geq 40$ years in China, Taiwan and South Korea, using symptom definitions approved by the International Continence Society (ICS) in 2002 [22]. Here we report QoL and mental health results from the study.

\section{Methods}

As the study methods are published in full elsewhere [23], they are described here in brief.

\section{Study design and population}

We conducted a cross-sectional, population-representative internet-based study in China, Taiwan and South Korea.
Inclusion criteria were age $\geq 40$ years, internet access and ability to read the local language. Pregnant women and individuals with a urinary tract infection during the previous month were excluded. The study was performed in compliance with the principles of the Declaration of Helsinki, Good Clinical Practice and the World Association for Social, Opinion and Market Research (ESOMAR) guidelines [24]. Informed consent was obtained from all participants.

Consumer survey panels were actively managed to ensure random sampling with representation of the target population in terms of age, sex and socioeconomic factors.

\section{Endpoints}

Instruments in the study were validated in the local language and included the following: the International Prostate Symptom Score (IPSS) [25]; other ICS symptoms questions (related to splitting/spraying, hesitancy, terminal dribble, urgency); Overactive Bladder Symptom Score (OABSS) [26]; the 12-item short-form health survey for measuring health-related QoL (HRQoL-SF12v2; possible scores for mental health domain and physical health domain range from 0 to 100, with higher scores indicating better health) [27]; Work Limitations Questionnaire (WLQ) [28]; Hospital Anxiety and Depression Scale (HADS; total score for both anxiety and depression classified as normal, 0-7, borderline abnormal, 8-10, or abnormal, 11-21) [29]. Presence of LUTS was based on ICS criteria (presence of voiding, storage or postmicturition symptom[s] with frequency $\geq 1$ in 5 times), with the exception that nocturia was defined as $\geq 2$ episodes per night (ICS definition for nocturia is $\geq 1$ episode per night; the higher threshold was chosen to avoid over-estimation) [22].

\section{Statistical analysis}

A minimum sample size of 384 respondents per group was needed for estimating LUTS affecting $50 \%$ of patients within five percentage points. Five different age groups $(40-44,45-49,50-54,55-60$ and $>60$ years) were planned for analysis, necessitating 1920 individuals per country. With an assumption that $\sim 28 \%$ of data would be non-evaluable, a total population of 8000 study participants was planned (4000 in China, 2000 in Taiwan and 2000 in South Korea). The initial data analyses were based on descriptive statistics. Workplace productivity 
analyses excluded individuals who selected 'does not apply to my job' as a response. Post-stratification weighting was performed to match the age and sex distributions of the populations in the respective countries. All significance testing was undertaken post hoc. Predictors of HADS scores were identified by logistic regression. The independent-samples t-test was used for the following: differences in HRQoL scores between men and women; differences in HRQoL scores between individuals with or without LUTS according to ICS criteria; relationship between HRQoL score and severity of overactive bladder $(\mathrm{OAB})$ according to the OABSS; differences in HADS anxiety and depression scores between individuals with or without LUTS according to ICS criteria; and the relationship between HADS anxiety and depression scores and OABSS. Associations between LUTS prevalence according to ICS criteria and workplace productivity were examined using the chi-square test. Analysis of variance (ANOVA) was used to assess differences in HRQoL score between individuals with different ICS symptom groups, and differences in HADS anxiety and depression scores between individuals with different ICS symptom groups. The relationships between HADS anxiety and depression scores and severity of $\mathrm{OAB}$ according to IPSS were also assessed by ANOVA.

\section{Results}

The survey sample and response rate for each country has been reported previously [23]. The study included a total of 8284 participants, of whom 4136 were from China, 2068 from Taiwan and 2080 from South Korea. Table 1 shows demographic characteristics of the population.

HRQoL scores were lower (i.e. worse) among individuals with versus without LUTS according to ICS criteria (Fig. 1; $p<0.001$ for both physical health domain and mental health domain). For the overall population with and without LUTS, the mean physical health domain scores were 61.1 (standard deviation [SD], 20.1) and 76.7 (17.0), respectively, and the mean mental health domain scores were 34.8 (12.7) and 43.7 (10.7). These differences were evident in all three countries. Men had higher (i.e. better) HRQoL scores than women, for both physical and mental health domains ( $p<0.001$ for both), but LUTS were associated with similar score reductions in both sexes. Individuals with all three ICS symptom groups had the lowest mean HRQoL scores (physical health domain: 52.3 [SD, 18.5]; mental health domain: 29.4 [11.5]; $p<0.001$ for both domains versus all other ICS symptom group combinations), and the presence of two symptom groups was generally associated with lower HRQoL scores than one (Table 2). The presence of voiding and storage symptoms was associated with
Table 1 Participants' demographic data. Table reproduced from Chapple et al. 2017 [23]

\begin{tabular}{|c|c|c|c|c|}
\hline & $\begin{array}{l}\text { China } \\
(n=4136)\end{array}$ & $\begin{array}{l}\text { Taiwan } \\
(n=2068)\end{array}$ & $\begin{array}{l}\text { South Korea } \\
(n=2080)\end{array}$ & $\begin{array}{l}\text { Overall } \\
(n=8284)\end{array}$ \\
\hline \multicolumn{5}{|l|}{ Sex } \\
\hline Men & $50.3 \%$ & $48.6 \%$ & $47.6 \%$ & $49.2 \%$ \\
\hline Women & $49.7 \%$ & $51.4 \%$ & $52.4 \%$ & $50.8 \%$ \\
\hline \multicolumn{5}{|l|}{ Age group } \\
\hline 40-44 years & $19.9 \%$ & $15.6 \%$ & $16.9 \%$ & $18.1 \%$ \\
\hline 45-49 years & $19.6 \%$ & $16.1 \%$ & $16.8 \%$ & $18.0 \%$ \\
\hline 50-54 years & $15.3 \%$ & $16.3 \%$ & $16.3 \%$ & $15.8 \%$ \\
\hline $55-59$ years & $12.7 \%$ & $14.9 \%$ & $14.4 \%$ & $13.7 \%$ \\
\hline$\geq 60$ years & $32.6 \%$ & $37.1 \%$ & $35.6 \%$ & $34.4 \%$ \\
\hline \multicolumn{5}{|l|}{ Education } \\
\hline High school or less & $28.0 \%$ & $39.3 \%$ & $30.3 \%$ & $31.4 \%$ \\
\hline Some college & $28.4 \%$ & $23.7 \%$ & $3.4 \%$ & $20.9 \%$ \\
\hline $\begin{array}{l}\text { College degree/ } \\
\text { college graduate }\end{array}$ & $40.2 \%$ & $28.2 \%$ & $57.0 \%$ & $41.4 \%$ \\
\hline Postgraduate & $3.5 \%$ & $8.8 \%$ & $9.4 \%$ & $6.3 \%$ \\
\hline \multicolumn{5}{|l|}{ Marital status } \\
\hline Single & $2.9 \%$ & $14.9 \%$ & $9.2 \%$ & $7.5 \%$ \\
\hline Divorced & $1.5 \%$ & $5.2 \%$ & $4.0 \%$ & $3.0 \%$ \\
\hline $\begin{array}{l}\text { Married/living } \\
\text { with partner }\end{array}$ & $91.7 \%$ & $72.8 \%$ & $81.6 \%$ & $84.5 \%$ \\
\hline Widow/widower & $3.2 \%$ & $6.3 \%$ & $4.5 \%$ & $4.3 \%$ \\
\hline $\begin{array}{l}\text { Prefer not to } \\
\text { answer }\end{array}$ & $0.8 \%$ & $0.7 \%$ & $0.7 \%$ & $0.7 \%$ \\
\hline \multicolumn{5}{|l|}{ Work status } \\
\hline Homemaker & $2.6 \%$ & $12.0 \%$ & $22.4 \%$ & $9.9 \%$ \\
\hline Retired & $28.7 \%$ & $16.9 \%$ & $6.0 \%$ & $20.1 \%$ \\
\hline Student & $0.0 \%$ & $0.1 \%$ & $0.2 \%$ & $0.1 \%$ \\
\hline Working, full-time & $62.6 \%$ & $60.0 \%$ & $53.9 \%$ & $59.8 \%$ \\
\hline Working, part-time & $3.7 \%$ & $6.2 \%$ & $8.0 \%$ & $5.4 \%$ \\
\hline Other work for pay & $0.4 \%$ & $0.8 \%$ & $3.2 \%$ & $1.2 \%$ \\
\hline Other & $1.1 \%$ & $1.9 \%$ & $3.7 \%$ & $2.0 \%$ \\
\hline Unemployed & $0.6 \%$ & $1.3 \%$ & $2.3 \%$ & $1.2 \%$ \\
\hline $\begin{array}{l}\text { Permanently } \\
\text { disabled/cannot } \\
\text { work due to ill } \\
\text { health }\end{array}$ & $0.1 \%$ & $0.8 \%$ & $0.4 \%$ & $0.4 \%$ \\
\hline
\end{tabular}

greater HRQoL impairment than any other pair of ICS symptom groups, with a mean physical health domain score of 58.4 (20.0) and a mean mental health domain score of 33.8 (13.2). Increasing severity of OAB, according to OABSS, was associated with decreasing HRQoL physical and mental health scores (Table 2; $p<0.001$ for individuals with versus without $\mathrm{OAB}$ ). These trends were similar in China, South Korea and Taiwan. 


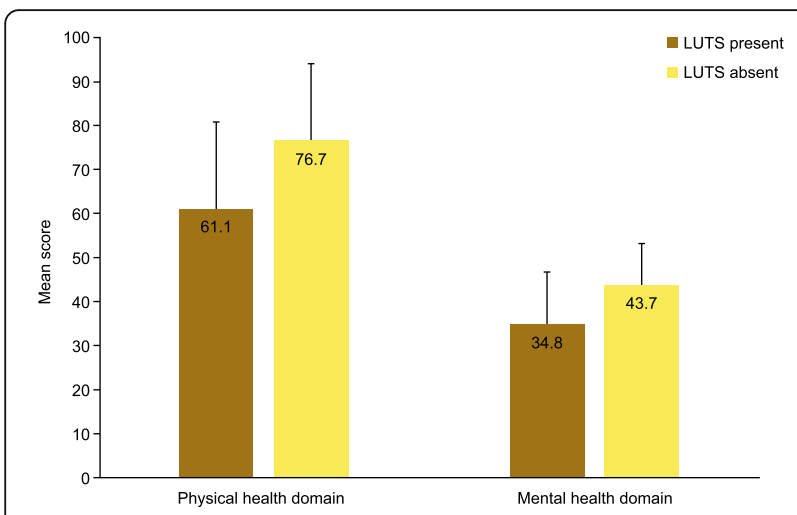

Fig. $1 \mathrm{HRQOL}$ scores (assessed using the 12-item short-form health survey) among individuals with or without LUTS according to ICS criteria. HRQOL health-related quality of life, ICS International Continence Society, LUTS lower urinary tract symptoms

The presence of LUTS according to ICS criteria was associated with statistically significantly impaired workplace productivity (Table $3 ; p=0.001$ for all eight domains, LUTS present versus LUTS absent). The best productivity was evident among individuals without LUTS, while productivity was worst in those with all three ICS symptom groups. Second worst results were obtained from individuals with voiding and storage symptoms. Compared with individuals without LUTS, productivity was least affected among individuals with only one ICS symptom group. The results showed a similar pattern across all eight items of the work limitations questionnaire. Impairment of workplace productivity (all eight items) was shown to increase with increasing severity of $\mathrm{OAB}$ (Table 3; $p=0.001$ for all eight domains, $\mathrm{OAB}$ present versus $\mathrm{OAB}$ absent).

Individuals with LUTS according to ICS criteria had higher (i.e. worse) scores for both anxiety and depression compared with those without LUTS (Fig. 2; $p<0.001$ for men, women and both sexes together). The mean anxiety score for the population with LUTS was 6.5 (SD, 3.7), compared with 4.0 (3.3) for the population without LUTS. The corresponding mean depression scores were 6.8 (4.3) and 4.2 (3.6). Women had higher HADS scores than men $(p<0.0001$ for both anxiety and depression), but the difference between individuals with versus without LUTS was similar in both sexes (Table 4). The highest (i.e. worst) HADS scores were observed among those with all three ICS symptom groups $(p<0.001$ versus all other ICS symptom group combinations), with mean scores for anxiety and depression of 8.0 (3.6) and 8.2 (4.3), respectively. Individuals with two symptom groups generally had higher HADS scores than those with one symptom group. HADS scores were also higher among individuals with versus without $\mathrm{OAB}(p<0.0001$ for both anxiety and depression). HADS scores increased markedly with increasing $\mathrm{OAB}$ severity assessed by OABSS: mean anxiety scores for individuals with no versus severe $\mathrm{OAB}$ were 4.9 (3.5) and 11.5 (4.3); the corresponding depression scores were 5.1 (4.0) and 11.5 (5.1). In addition, statistically significant relationships were observed between HADS scores and IPSS-measured symptom severity (increased IPSS severity associated with

Table 2 HRQOL by LUTS and OABSS

\begin{tabular}{|c|c|c|c|c|}
\hline & \multicolumn{2}{|l|}{ Physical health domain } & \multicolumn{2}{|l|}{ Mental health domain } \\
\hline & $\begin{array}{l}\text { Mean score } \\
\text { (standard deviation) }^{\mathrm{a}}\end{array}$ & $\begin{array}{l}p \text {-value for comparison } \\
\text { vs. No LUTS or No OAB }\end{array}$ & $\begin{array}{l}\text { Mean score } \\
\text { (standard deviation) }^{a}\end{array}$ & $\begin{array}{l}p \text {-value for comparison } \\
\text { vs. No LUTS or No OAB }\end{array}$ \\
\hline \multicolumn{5}{|l|}{ LUTS (ICS criteria) } \\
\hline No LUTS & $76.7(17.0)$ & N/A & $43.7(10.7)$ & N/A \\
\hline Voiding Only & $71.5(17.4)$ & $<0.005$ & $40.9(10.9)$ & $<0.005$ \\
\hline Storage Only & $68.2(18.5)$ & $<0.005$ & $38.9(12.0)$ & $<0.005$ \\
\hline PM Only & $68.2(18.0)$ & $<0.005$ & $38.6(12.5)$ & $<0.005$ \\
\hline Voiding + Storage & $58.4(20.0)$ & $<0.005$ & $33.8(13.2)$ & $<0.005$ \\
\hline Voiding + PM & $68.8(17.9)$ & $<0.005$ & $39(12.0)$ & $<0.005$ \\
\hline Storage + PM & $63.6(19.0)$ & $<0.005$ & $36.2(11.6)$ & $<0.005$ \\
\hline Voiding + Storage + PM & $52.3(18.5)$ & $<0.005$ & $29.4(11.5)$ & $<0.005$ \\
\hline \multicolumn{5}{|l|}{ OABSS } \\
\hline No OAB & $71.4(18.7)$ & N/A & $40.8(11.8)$ & N/A \\
\hline Mild OAB & $58.6(18.2)$ & $<0.0005$ & $33.3(11.6)$ & $<0.0005$ \\
\hline Moderate OAB & $47.7(16.8)$ & $<0.0005$ & $26.7(10.7)$ & $<0.0005$ \\
\hline Severe $O A B$ & $33.6(15.6)$ & $<0.0005$ & $18.9(9.5)$ & $<0.0005$ \\
\hline Overall & $67.1(20.4)$ & & $38.2(12.8)$ & \\
\hline
\end{tabular}

ICS International Continence Society, LUTS lower urinary tract symptoms, OAB overactive bladder, OABSS Overactive Bladder Symptom Score, PM post-micturition ${ }^{a}$ data are for both sexes and all three countries combined 


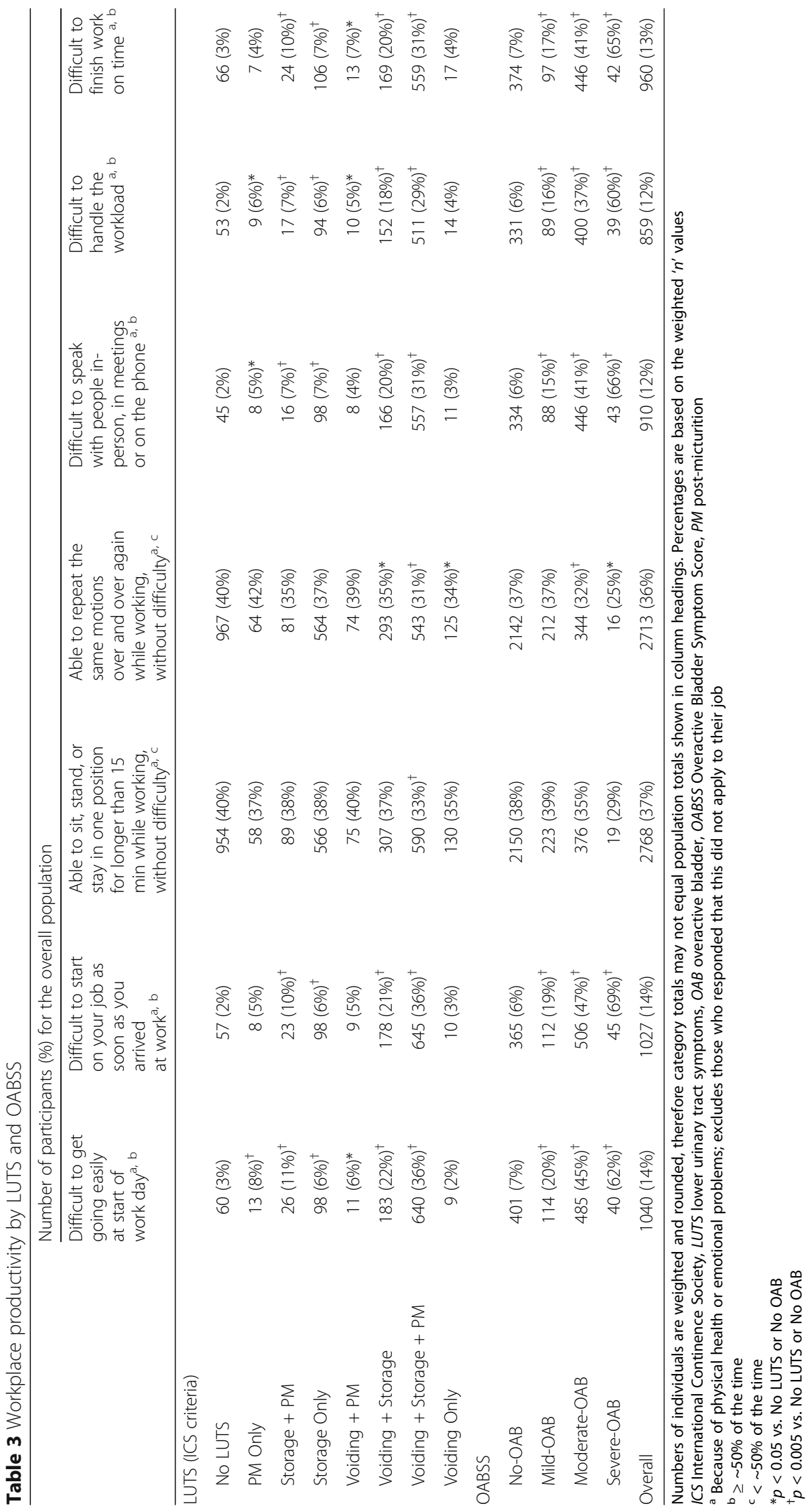



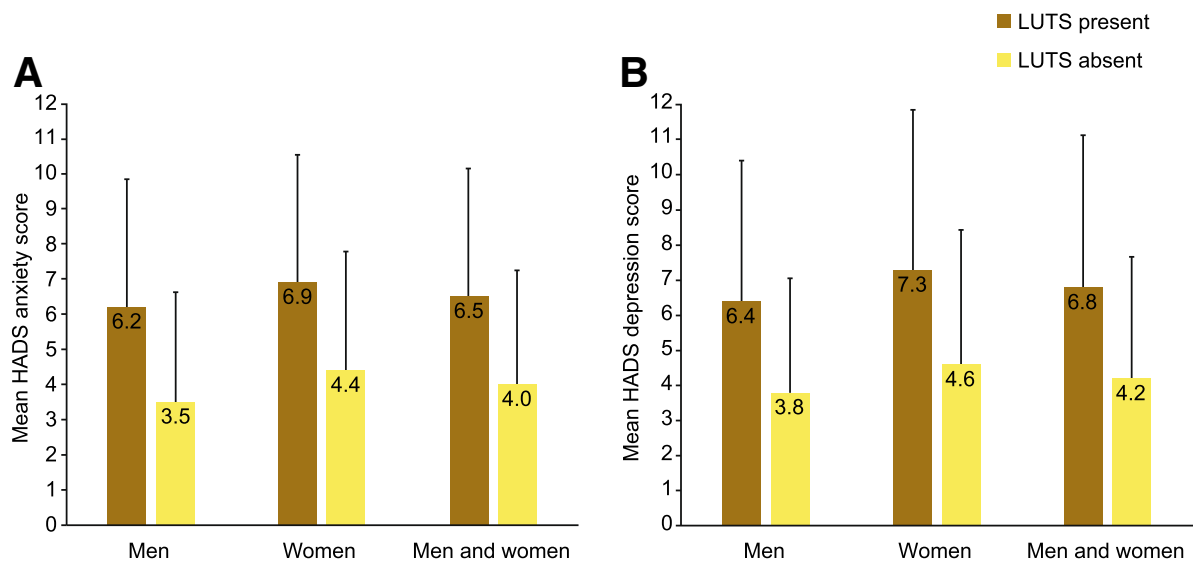

Fig. 2 HADS by LUTS according to ICS criteria: a anxiety and $\mathbf{b}$ depression. HADS Hospital Anxiety and Depression Scale, ICS International Continence Society, LUTS lower urinary tract symptoms

higher HADS anxiety and depression scores; $p<0.001$ ). The associations between HADS scores and OABSS/ IPSS severity were evident in both men and women. Statistically significant predictors of high HADS scores $(\geq 8$, indicating clinically relevant levels of anxiety and depression [30]) are shown in Table 5. Urgency with fear of leaking and stress incontinence (different causes) were associated with high depression and anxiety scores in both men and women. Incomplete emptying was a predictor of high scores for anxiety and depression in

Table 4 HADS by LUTS, IPSS and OABSS

\begin{tabular}{|c|c|c|c|c|c|c|}
\hline & \multicolumn{3}{|c|}{ Anxiety score ${ }^{a}$} & \multicolumn{3}{|c|}{ Depression score ${ }^{a}$} \\
\hline & Men & Women & $\begin{array}{l}\text { Men and } \\
\text { women }\end{array}$ & Men & Women & $\begin{array}{l}\text { Men and } \\
\text { women }\end{array}$ \\
\hline \multicolumn{7}{|l|}{ LUTS (ICS criteria) } \\
\hline No LUTS & $3.5(3.1)$ & $4.4(3.4)$ & $4.0(3.3)$ & $3.8(3.3)$ & $4.6(3.9)$ & $4.2(3.6)$ \\
\hline Voiding Only & $4.8(3.4)^{\dagger}$ & $5.3(3)$ & $4.9(3.3)^{\dagger}$ & $5.5(4)^{\dagger}$ & $6.3(4.2)^{\dagger}$ & $5.6(4)^{\dagger}$ \\
\hline Storage Only & $5.1(3.4)^{\dagger}$ & $5.7(3.4)^{\dagger}$ & $5.5(3.4)^{\dagger}$ & $5.2(3.8)^{\dagger}$ & $6(4.1)^{\dagger}$ & $5.7(4)^{\dagger}$ \\
\hline PM Only & $4.6(3.1)$ & $5.8(3.1)^{*}$ & $5.1(3.2)^{+}$ & $5(3.4)$ & $6.7(4.4)^{\dagger}$ & $5.7(3.9)^{\dagger}$ \\
\hline Voiding + Storage & $6.1(3.5)^{\dagger}$ & $7(3.6)^{\dagger}$ & $6.5(3.6)^{\dagger}$ & $6.4(3.8)^{\dagger}$ & $7.4(4.3)^{\dagger}$ & $6.9(4.1)^{\dagger}$ \\
\hline Voiding + PM & $5.1(3.5)^{\dagger}$ & $6.6(3.6)^{\dagger}$ & $5.4(3.5)^{\dagger}$ & $5.8(3.9)^{\dagger}$ & $7.7(4.9)^{\dagger}$ & $6.2(4.2)^{\dagger}$ \\
\hline Storage + PM & $6(3.4)^{\dagger}$ & $6.7(3.3)^{\dagger}$ & $6.4(3.4)^{\dagger}$ & $6.1(3.8)^{\dagger}$ & $7.3(4.4)^{\dagger}$ & $6.7(4.1)^{\dagger}$ \\
\hline Voiding + Storage + PM & $7.5(3.6)^{\dagger}$ & $8.7(3.5)^{\dagger}$ & $8.0(3.6)^{\dagger}$ & $7.5(3.9)^{\dagger}$ & $9.2(4.6)^{\dagger}$ & $8.2(4.3)^{\dagger}$ \\
\hline \multicolumn{7}{|l|}{ OABSS } \\
\hline No OAB & $4.5(3.5)$ & $5.2(3.5)$ & $4.9(3.5)$ & $4.8(3.7)$ & $5.5(4.2)$ & $5.1(4.0)$ \\
\hline Mild OAB & $6.6(3.5)^{\dagger}$ & $7.3(3.2)^{\dagger}$ & $6.9(3.4)^{\dagger}$ & $7.1(3.7)^{\dagger}$ & $7.7(4)^{\dagger}$ & $7.4(3.9)^{\dagger}$ \\
\hline Moderate OAB & $8.2(3.4)^{\dagger}$ & $8.7(3.5)^{\dagger}$ & $8.5(3.5)^{\dagger}$ & $8.1(3.8)^{\dagger}$ & $9.3(4.6)^{\dagger}$ & $8.7(4.3)^{\dagger}$ \\
\hline Severe $O A B$ & $10.9(4.3)^{\dagger}$ & $11.9(4.4)^{\dagger}$ & $11.5(4.3)^{\dagger}$ & $10.7(3.6)^{\dagger}$ & $12.1(5.9)^{\dagger}$ & $11.5(5.1)^{\dagger}$ \\
\hline \multicolumn{7}{|l|}{ IPSS } \\
\hline No Symptom & $3(3.2)$ & $3.8(3.5)$ & $3.4(3.4)$ & $3.5(3.5)$ & $4.5(4)$ & $4(3.8)$ \\
\hline Mild & $4.4(3.3)^{\dagger}$ & $5.2(3.4)^{\dagger}$ & $4.8(3.4)^{\dagger}$ & $4.6(3.5)^{\dagger}$ & $5.3(4)^{\dagger}$ & $5(3.8)^{\dagger}$ \\
\hline Moderate & $6.5(3.4)^{\dagger}$ & $7.5(3.3)^{\dagger}$ & $6.9(3.4)^{\dagger}$ & $6.8(3.8)^{\dagger}$ & $8(4.4)^{\dagger}$ & $7.3(4.1)^{\dagger}$ \\
\hline Severe & $9.2(3.9)^{\dagger}$ & $10(3.7)^{\dagger}$ & $9.6(3.9)^{\dagger}$ & $9.1(4.1)^{\dagger}$ & $10.4(4.7)^{\dagger}$ & $9.8(4.4)^{\dagger}$ \\
\hline Overall & $5.2(3.7)$ & $5.9(3.8)$ & $5.5(3.8)$ & $5.4(3.9)$ & $6.2(4.5)$ & $5.8(4.2)$ \\
\hline
\end{tabular}

HADS Hospital Anxiety and Depression Scale, ICS International Continence Society, IPSS International Prostate Symptom Score, LUTS lower urinary tract symptoms, $O A B$ overactive bladder, $O A B S S$ overactive bladder symptom score, $P M$ post-micturition

${ }^{*} p<0.05$ vs. No LUTS, No OAB or No Symptom

${ }^{+} p<0.005$ vs. No LUTS, No OAB or No Symptom

${ }^{a}$ mean scores (standard deviation) for all three countries combined 
women, while perceived frequency and terminal dribble were predictors of high scores for both parameters in men as well as anxiety in women.

\section{Discussion}

This study provides strong evidence that LUTS are associated with impaired QoL, reduced workplace productivity, and increased tendency towards anxiety and depression. These findings are evident in both men and women from all three countries included in the study. Individuals with all three ICS symptom groups showed greater impairment than those with two ICS symptom groups, and the presence of two ICS symptom groups was associated with greater impairment than one symptom group. Voiding and storage were associated with greater QoL impairment than other pairs of symptom groups. Workplace productivity decreased with increasing severity of $O A B$, while HADS scores deteriorated with increasing OAB and IPSS severity. Urgency with fear of leaking was a significant predictor of high HADS scores for anxiety and depression in both men and women.

Overall, our results are consistent with data from previous studies assessing the impact of LUTS on QoL and mental health in countries outside Asia. In the EpiLUTS study, conducted in 30,000 adults aged $\geq 40$ years in Sweden, UK and USA, similar methods to the current study were used for assessing LUTS (ICS criteria), HRQoL (SF-12) and mental health (HADS) [9]. As in our study, deteriorations in physical and mental components of the SF-12, as well as anxiety and depression scores, were most pronounced among individuals with all three ICS symptom groups. A study of urinary incontinence in women from France, Germany, UK and USA $(N=1203)$ showed that the impact of symptoms on HRQoL (measured using the International Consultation on Incontinence Modular Questionnaire Lower Urinary Tract Symptoms Quality of Life [ICIQ-LUTSqol]) increased with increasing symptom severity [6]. Evidence that QoL impairment increases with symptom severity was also provided by a Mexican study conducted in a population aged $\geq 70$ years $(N=1124)$ : individuals with severe urinary incontinence had worse self-perceived health status and greater disability than those with less severe symptoms [10]. In addition, this study reported increased symptoms of depression among those with severe incontinence. Data from the UREPIK and BACH studies, which were performed in men aged 40-79 years $(N=6486)$ from five cities (Boxmeer, the Netherlands; Auxerre, France; Birmingham, UK; Seoul, South Korea and Boston, USA), also showed that QoL decreased with increasing severity of LUTS [12]. A 10-point increase in IPSS was associated with a 3.3-point reduction in SF-12 physical health component score, and a 1.4-3.4-point reduction in the mental health component score [12]. A US study reported that storage but not voiding symptoms was significantly associated with anxiety and depression [5]. Our study showed some trends towards greater increases in anxiety and depression scores among individuals with storage versus voiding symptoms, but the differences were small.

Studies conducted in Asian populations also reported similar findings to our study. South Korean women with $\mathrm{OAB}$ or stress urinary incontinence (SUI) have been shown to have lower quality of life (i.e. higher scores for all King's Health Questionnaire domains) than controls [15]. The same study reported lower Short Form-36 (SF-36) scores versus controls for four out of eight domains in women with $\mathrm{OAB}$, and for one domain in women with SUI. A door-to-door survey of South Korean men aged $\geq 40$ years showed that generic health status and workplace productivity were impaired among individuals with LUTS compared with those without LUTS [7]. Increased symptoms of major depression were also observed in men with LUTS. A third South Korean study involved 625 men and women with $\mathrm{OAB}$ [31]. Increasing severity of incontinence was associated with significantly lower QoL (measured using the Incontinence-Specific

Table 5 Significant predictors of HADS scores $\geq 8$

\begin{tabular}{|c|c|c|}
\hline & Men & Women \\
\hline HADS anxiety score & $\begin{array}{l}\text { Voiding symptoms: Straining, terminal } \\
\text { dribble } \\
\text { Storage symptoms: Perceived frequency, } \\
\text { nocturia, urgency with fear of leaking, } \\
\text { and stress incontinence (in relation to } \\
\text { sneezing, exercising, nocturnal enuresis } \\
\text { or sexual activity) }\end{array}$ & $\begin{array}{l}\text { Voiding symptoms: Terminal dribble } \\
\text { Storage symptoms: Perceived frequency, } \\
\text { nocturia, urgency with fear of leaking, and } \\
\text { stress incontinence (nocturnal enuresis) } \\
\text { Post-micturition symptoms: Incomplete } \\
\text { emptying }\end{array}$ \\
\hline HADS depression score & $\begin{array}{l}\text { Voiding symptoms: Terminal dribble } \\
\text { Storage symptoms: Perceived frequency, } \\
\text { urgency, urgency with fear of leaking, } \\
\text { urgency incontinence (how often), and } \\
\text { stress incontinence (in relation to coughing } \\
\text { or sexual activity) }\end{array}$ & $\begin{array}{l}\text { Storage symptoms: Nocturia, urgency with } \\
\text { fear of leaking, and stress incontinence } \\
\text { (in relation to laughing or for no reason) } \\
\text { Post-micturition symptoms: } \\
\text { Incomplete emptying }\end{array}$ \\
\hline
\end{tabular}


Quality of Life Instrument), increased symptom bother, poorer health-related utility (according to EQ5D), increased expenditure on incontinence pads, and increased interference with work and regular activities. In the same study, frequency, urgency and nocturia were independently associated with QoL impairment [31]. In Taiwanese women with SUI, significant correlations between the severity of incontinence and incontinence-related QoL have been observed [14]. Another study of Taiwanese women (age range: 35-64 years; $N=4661$ ) reported reduced SF-36 scores, including physical and mental components, among individuals with urinary incontinence [8]. This study also showed that urinary incontinence had a greater impact on mental health-related HRQoL than diabetes, hyperlipidaemia, and chronic kidney disease. A third Taiwanese study showed that women with mixed urinary incontinence had lower QoL than those with urge incontinence or stress incontinence [32]. In China, HRQoL was assessed in individuals with LUTS and compared with data for the normal population [33]. Reduced scores were observed among the population with LUTS for the general health and vitality domains and for the physical component, although LUTS was associated with a higher role emotion domain score. HRQoL impairment increased with increased LUTS severity. In another Chinese study, data from $>1000$ adults showed that increasing episodes of nocturia was an independent predictor of impaired nocturia-related QoL [16].

Our findings also reflect previous Asian mental health data. In Taiwan, the prevalence of depression or anxiety has been found to be twice as high among individuals with LUTS versus matched controls ( $11.45 \%$ vs. $5.72 \%)$ [34]. Similarly, the odds ratio of depression in Korean men with versus without LUTS has been reported to be 2.87 [35]. A study performed in Hong Kong reported that the relationship between LUTS and depressive symptoms is robust after adjustment for other factors associated with depression such as divorce, cardiac disease and smoking [36].

Our study suggests considerable scope to reduce the overall burden of LUTS by increasing the percentage of patients who consult healthcare professionals, which will help patients gain access to the most effective available treatment for their condition. A variety of treatments that can be prescribed for LUTS have been shown to improve patients' QoL and/or mental health (e.g. drug treatment such as alpha blockers or antimuscarinics, surgical options such as transobturator tape or transurethral resection, botulinum toxin injections) [37-46].

The survey population is an important strength of our study. Younger individuals were not included because of previous data showing that LUTS are highly prevalent above the age of 40 [2] and numerous other epidemiological studies have focused on populations aged $\geq 40$ years $[6,7,9,12,47]$. Additional strengths include the large number of participants and the use of wellestablished instruments to determine the presence and severity of LUTS and their effects on QoL and mental health. Our survey was conducted in countries with the highest internet penetration rates in Asia (South Korea, 92\%; Taiwan, $84 \%$ and China 52\%) [48]. Use of the internet to conduct a survey encourages full and honest responses to sensitive questions - there can be a tendency for biased answers when questions are asked by an interviewer [49]. On the other hand, we cannot be certain that results among individuals without internet access would be the same as those reported here. Also, when completing a questionnaire online, study participants may potentially interpret questions differently from those asked by a healthcare professional as interviewer. Although our results are similar to other studies around the globe, our study is limited by statistical analyses being undertaken post hoc; ideally these should have been identified a priori. The study was not designed to assess costs associated with LUTS, although impairment of workplace productivity indicates a financial impact and a health economic evaluation may have been useful. Previous investigations have shown that the economic burden of LUTS is significant (e.g. estimated annual costs up to $\$ 32$ billion in the USA) $[50,51]$.

\section{Conclusions}

In conclusion, this international study demonstrates the association of both LUTS and increasing OAB severity with impairment of QoL, workplace productivity and mental health in three Asian countries. These results are consistent with previous studies, and highlight the need to ensure that individuals with LUTS consult healthcare professionals to receive appropriate and effective treatment.

\section{Abbreviations}

ANOVA: Analysis of variance; HADS: Hospital anxiety and depression scale; HRQoL-SF12v2: 12-item short-form health survey for measuring healthrelated quality of life; ICIQ-LUTSqol: International Consultation on Incontinence Modular Questionnaire Lower Urinary Tract Symptoms Quality of Life; ICS: International Continence Society; IPSS: International Prostate Symptom Score; LUTS: Lower urinary tract symptoms; OABSS: Overactive bladder symptom score; QoL: Quality of life; SD: Standard deviation; WLQ: Work limitations

\section{Acknowledgements}

The authors would like to thank the participants of the study for their time, Nanjangud Shankar Narasimhamurthy and Koni Raviprakash for statistical analyses and Dr. Ming Liu for intellectual input into the manuscript. Medical writing support was provided by Ken Sutor, BSc and Jackie van Bueren, BSc of Envision Scientific Solutions. 


\section{Funding}

This study was designed and funded by Astellas Pharma Singapore Pte. Ltd. Medical writing support was funded by Astellas Pharma Global Development.

\section{Availability of data and materials}

The datasets will not be available on a publically available website, but it may be possible to provide access to anonymized data.

\section{Authors' contributions}

$\mathrm{K}-\mathrm{SL}, \mathrm{TKY}, \mathrm{LL}, \mathrm{JW}, \mathrm{Y}-\mathrm{CC}, \mathrm{S}-\mathrm{PL}, \mathrm{RC}$ and BS were involved in the study conception and design, analysis and interpretation of data, drafting the manuscript, and critical revision of the manuscript for important intellectual content. BS was additionally involved in acquisition of data and statistical analysis. All authors read and approved the final manuscript.

\section{Ethics approval and consent to participate}

The study was based on a survey, with participants selected via consumer survey panels and as such it was not considered necessary to submit for Institutional Review Board approval. However, principles of the Declaration of Helsinki were followed; the study was performed in compliance with Good Clinical Practice and followed the World Association for Social, Opinion and Market Research (ESOMAR) guidelines that enshrine legal and ethical considerations of panel research, including respondent rights affecting patients/consumers who undertake market research surveys.

Informed consent was obtained from all patients being included in the study.

\section{Consent for publication}

Not applicable.

\section{Competing interests}

K-SL, T-KY, LL, JW, Y-CC, and S-PL: acted as a consultant for Astellas during a meeting to discuss the publications from the study. T-KY also received grants and personal fees from Astellas to act as a consultant. RC: was an employee of Astellas Pharma Singapore Pte Ltd. during the conduct of the study and BS is a current employee of Astellas Pharma Singapore Pte Ltd.

\section{Publisher's Note}

Springer Nature remains neutral with regard to jurisdictional claims in published maps and institutional affiliations.

\section{Author details}

'Department of Urology, Samsung Medical Center, Sungkyunkwan University School of Medicine, Seoul, Korea. ${ }^{2}$ Department of Urology, Nowon Eulji Medical Center, Eulji University School of Medicine, 68, Hangeulbiseok-ro, Nowon-gu, Seoul, Korea. ${ }^{3}$ Department of Urology, China Rehabilitation Research Center, Capital Medical University, Beijing, China. ${ }^{4}$ Department of Urology, Beijing Hospital, Beijing, China. ${ }^{5}$ Department of Urology, Kaohsiung Chang Gung Memorial Hospital, Chang Gung University College of Medicine, Kaohsiung, Taiwan. ${ }^{6}$ Department of Urology, National Taiwan University Hospital and College of Medicine, Taipei, Taiwan. ${ }^{7}$ Astellas Pharma Singapore Pte. Ltd., Singapore, Singapore. ${ }^{8}$ Present address: 5 Pemimpin Drive, \#19-03 Seasons View, Singapore, Singapore.

Received: 29 June 2017 Accepted: 30 October 2017

Published online: 21 November 2017

\section{References}

1. Coyne KS, Sexton CC, Thompson CL, Milsom I, Irwin D, Kopp ZS, et al. The prevalence of lower urinary tract symptoms (LUTS) in the USA, the UK and Sweden: results from the epidemiology of LUTS (EpiLUTS) study. BJU Int. 2009;104:352-60

2. Irwin DE, Milsom I, Hunskaar S, Reilly K, Kopp Z, Herschorn S, et al. Populationbased survey of urinary incontinence, overactive bladder, and other lower urinary tract symptoms in five countries: results of the EPIC study. Eur Urol. 2006:50:1306-14.

3. Lee YS, Lee KS, Jung JH, Han DH, Oh SJ, Seo JT, et al. Prevalence of overactive bladder, urinary incontinence, and lower urinary tract symptoms: results of Korean EPIC study. World J Urol. 2011;29:185-90.
4. Wang $Y$, Hu H, Xu K, Wang X, Na Y, Kang X. Prevalence, risk factors and the bother of lower urinary tract symptoms in China: a population-based survey. Int Urogynecol J. 2015:26:911-9.

5. Martin S, Vincent A, Taylor AW, Atlantis E, Jenkins A, Januszewski A, et al. Lower urinary tract symptoms, depression, anxiety and systemic inflammatory factors in men: a population-based cohort study. PLoS One. 2015;10:e0137903.

6. Abrams P, Smith AP, Cotterill N. The impact of urinary incontinence on health-related quality of life (HRQoL) in a real-world population of women aged 45-60 years: results from a survey in France, Germany, the UK and the USA. BJU Int. 2015:115:143-52.

7. Kim TH, Han DH, Ryu DS, Lee KS. The impact of lower urinary tract symptoms on quality of life, work productivity, depressive symptoms, and sexuality in Korean men aged 40 years and older: a population-based survey. Int Neurourol J. 2015; 19:120-9.

8. Horng SS, Huang N, Wu SI, Fang YT, Chou YJ, Chou P. The epidemiology of urinary incontinence and it's influence on quality of life in Taiwanese middle-aged women. Neurourol Urodyn. 2013;32:371-6.

9. Coyne KS, Wein AJ, Tubaro A, Sexton CC, Thompson CL, Kopp ZS, et al. The burden of lower urinary tract symptoms: evaluating the effect of LUTS on health-related quality of life, anxiety and depression: EpiLUTS. BJU Int. 2009; 103(Suppl 3):4-11.

10. Aguilar-Navarro S, Navarrete-Reyes AP, Grados-Chavarría BH, Garcia-Lara JM, Amieva $\mathrm{H}$, Avila-Funes JA. The severity of urinary incontinence decreases health-related quality of life among community-dwelling elderly. J Gerontol A Biol Sci Med Sci. 2012;67:1266-71.

11. Currie CJ, McEwan P, Poole CD, Odeyemi IA, Datta SN, Morgan CL. The impact of the overactive bladder on health-related utility and quality of life. BJU Int. 2006;97: 1267-72.

12. Robertson C, Link CL, Onel E, Mazzetta C, Keech M, Hobbs R, et al. The impact of lower urinary tract symptoms and comorbidities on quality of life: the BACH and UREPIK studies. BJU Int. 2007:99:347-54.

13. Sexton CC, Coyne KS, Thompson C, Bavendam T, Chen Cl, Markland A. Prevalence and effect on health-related quality of life of overactive bladder in older Americans: results from the epidemiology of lower urinary tract symptoms study. J Am Geriatr Soc. 2011;59:1465-70.

14. Huang WC, Yang SH, Yang SY, Yang E, Yang JM. The correlations of incontinence-related quality of life measures with symptom severity and pathophysiology in women with primary stress urinary incontinence. World J Urol. 2010;28:619-23.

15. Oh SJ, Ku JH. Impact of stress urinary incontinence and overactive bladder on micturition patterns and health-related quality of life. Int Urogynecol J Pelvic Floor Dysfunct. 2007;18:65-71.

16. Zhang X, Zhang J, Chen J, Zhang C, Li Q, Xu T, et al. Prevalence and risk factors of nocturia and nocturia-related quality of life in the Chinese population. Urol Int. 2011;86:173-8

17. Rom M, Schatzl G, Swietek N, Rucklinger E, Kratzik C. Lower urinary tract symptoms and depression. BJU Int. 2012;110:E918-21.

18. Litman HJ, Steers WD, Wei JT, Kupelian V, Link CL, McKinlay JB, et al. Relationship of lifestyle and clinical factors to lower urinary tract symptoms: results from Boston area community health survey. Urology. 2007;70:916-21.

19. Hsieh $\mathrm{CH}$, Kuo TC, Hsu CS, Chang ST, Lee MC. Nocturia among women aged 60 or older in Taiwan. Aust N Z J Obstet Gynaecol. 2008:48:312-6.

20. Norby B, Nordling J, Mortensen S. Lower urinary tract symptoms in the Danish population: a population-based study of symptom prevalence, health-care seeking behavior and prevalence of treatment in elderly males and females. Eur Urol. 2005:47:817-23.

21. Kuritzky L. Role of primary care clinicians in the diagnosis and treatment of LUTS and BPH. Rev Urol. 2004;6(Suppl 9):S53-9.

22. Abrams $P$, Cardozo L, Fall M, Griffiths D, Rosier P, Ulmsten U, et al. The standardisation of terminology of lower urinary tract function: report from the standardisation sub-committee of the international continence society. Neurourol Urodyn. 2002:21:167-78.

23. Chapple C, Castro-Díaz D, Chuang YC, Lee KS, Liao L, Liu SP, et al. Prevalence of LUTS in China, Taiwan and South Korea: results from a cross-sectional, population-based study. Adv Ther. 2017. doi:10.1007/s12325-017-0577-9

24. World Association for Social Opinion and Market Research. ESOMAR guideline for online research. Available at: https://www.esomar.org/uploads/ public/knowledge-and-standards/codes-and-guidelines/ESOMAR Guidelinefor-online-research.pdf. Accessed 6 Nov 2017. 
25. Barry MJ, Fowler FJ Jr, O'Leary MP, Bruskewitz RC, Holtgrewe HL, Mebust WK, et al. The American urological association symptom index for benign prostatic hyperplasia. The measurement Committee of the American Urological Association. J Urol. 1992;148:1549-57. discussion 64

26. Homma Y, Yoshida M, Seki N, Yokoyama O, Kakizaki H, Gotoh M, et al. Symptom assessment tool for overactive bladder syndrome - overactive bladder symptom score. Urology. 2006;68:318-23.

27. Ware J Jr, Kosinski M, Keller SD. A 12-item short-form health survey: construction of scales and preliminary tests of reliability and validity. Med Care. 1996;34:220-33.

28. Lerner D, Amick BC 3rd, Rogers WH, Malspeis S, Bungay K, Cynn D. The work limitations questionnaire. Med Care. 2001;39:72-85.

29. Zigmond AS, Snaith RP. The hospital anxiety and depression scale. Acta Psychiatr Scand. 1983;67:361-70.

30. Bjelland I, Dahl AA, Haug TT, Neckelmann D. The validity of the hospital anxiety and depression scale. An updated literature review. J Psychosom Res. 2002;52:69-77.

31. Lee KS, Choo MS, Seo JT, Oh SJ, Kim HG, Ng K, et al. Impact of overactive bladder on quality of life and resource use: results from Korean burden of incontinence study (KOBIS). Health Qual Life Outcomes. 2015;13:89.

32. Tsai YC, Liu CH. Urinary incontinence among Taiwanese women: an outpatient study of prevalence, comorbidity, risk factors, and quality of life. Int Urol Nephrol. 2009:41:795-803.

33. Choi EP, Lam CL, Chin WY. The health-related quality of life of Chinese patients with lower urinary tract symptoms in primary care. Qual Life Res. 2014;23:2723-33

34. Lung-Cheng Huang C, Ho CH, Weng SF, Hsu YW, Wang JJ, Wu MP. The association of healthcare seeking behavior for anxiety and depression among patients with lower urinary tract symptoms: a nationwide population-based study. Psychiatry Res. 2015;226:247-51.

35. Jeong WS, Choi HY, Nam JW, Kim SA, Choi BY, Moon HS, et al. Men with severe lower urinary tract symptoms are at increased risk of depression. Int Neurourol J. 2015;19:286-92.

36. Wong SY, Hong A, Leung J, Kwok T, Leung PC, Woo J. Lower urinary tract symptoms and depressive symptoms in elderly men. J Affect Disord. 2006;96:83-8.

37. Akin Y, Gulmez H, Ucar M, Yucel S. The effect of first dose of tamsulosin on flow rate and its predictive ability on the improvement of LUTS in men with BPH in the mid-term. Int Urol Nephrol. 2013;45:45-51.

38. Cañete $\mathrm{P}$, Ortiz E, Domingo S, Cano A. Transobturator suburethral tape in the treatment of stress urinary incontinence: efficacy and quality of life after 5 year follow up. Maturitas. 2013;74:166-71.

39. Game X, Khan S, Panicker JN, Kalsi V, Dalton C, Elneil S, et al. Comparison of the impact on health-related quality of life of repeated detrusor injections of botulinum toxin in patients with idiopathic or neurogenic detrusor overactivity. BJU Int. 2011;107:1786-92.

40. Hirakawa T, Suzuki S, Kato K, Gotoh M, Yoshikawa Y. Randomized controlled trial of pelvic floor muscle training with or without biofeedback for urinary incontinence. Int Urogynecol J. 2013;24:1347-54.

41. Innerkofler PC, Guenther V, Rehder P, Kopp M, Nguyen-Van-Tam DP Giesinger JM, et al. Improvement of quality of life, anxiety and depression after surgery in patients with stress urinary incontinence: results of a longitudinal short-term follow-up. Health Qual Life Outcomes. 2008;6:72.

42. Kafri R, Deutscher D, Shames J, Golombp J, Melzer I. Randomized trial of a comparison of rehabilitation or drug therapy for urgency urinary incontinence: 1-year follow-up. Int Urogynecol J. 2013;24:1181-9.

43. Quek KF, Low WY, Razack AH, Loh CS. The psychological effects of treatments for lower urinary tract symptoms. BJU Int. 2000;86:630-3.

44. Quek KF, Razack AH, Chua CB, Low WY, Loh CS. Effect of treating lower urinary tract symptoms on anxiety, depression and psychiatric morbidity: a one-year study. Int J Urol. 2004;11:848-55.

45. Rogers R, Bachmann G, Jumadilova Z, Sun F, Morrow JD, Guan Z, et al. Efficacy of tolterodine on overactive bladder symptoms and sexual and emotional quality of life in sexually active women. Int Urogynecol J Pelvic Floor Dysfunct. 2008;19:1551-7.

46. van Kerrebroeck P, Chapple C, Drogendijk T, Klaver M, Sokol R, Speakman M, et al. Combination therapy with solifenacin and tamsulosin oral controlled absorption system in a single tablet for lower urinary tract symptoms in men: efficacy and safety results from the randomised controlled NEPTUNE trial. Eur Urol. 2013;64:1003-12.
47. Araki I, Tsuchida T, Nomura T, Fukasawa M, Takihana Y, Koyama N, et al. Differential impact of lower urinary tract symptoms on generic and disease-specific quality of life in men and women. Urol Int. 2008;81:60-5.

48. Internet World Stats. Internet usage in Asia. Available at: http://www. internetworldstats.com/. Accessed 6 Nov 2017.

49. Coyne KS, Sexton CC, Kopp ZS, Luks S, Gross A, Irwin D, et al. Rationale for the study methods and design of the epidemiology of lower urinary tract symptoms (EpiLUTS) study. BJU Int. 2009;104:348-51.

50. Levy R, Muller N. Urinary incontinence: economic burden and new choices in pharmaceutical treatment. Adv Ther. 2006;23:556-73.

51. Tapia Cl, Khalaf K, Berenson K, Globe D, Chancellor M, Carr LK. Healthrelated quality of life and economic impact of urinary incontinence due to detrusor overactivity associated with a neurologic condition: a systematic review. Health Qual Life Outcomes. 2013;11:13.

\section{Submit your next manuscript to BioMed Central and we will help you at every step:}

- We accept pre-submission inquiries

- Our selector tool helps you to find the most relevant journal

- We provide round the clock customer support

- Convenient online submission

- Thorough peer review

- Inclusion in PubMed and all major indexing services

- Maximum visibility for your research

Submit your manuscript at www.biomedcentral.com/submit
Biomed Central 